\title{
Integración religiosa y social de los conversos en las comunidades de la diáspora sefardí occidental a la luz de fuentes inquisitoriales*
}

\author{
Aliza Moreno-Goldschmidt** \\ Hebrew University of Jerusalem
}

\begin{abstract}
Paralelamente al proceso de emigración desde la Península Ibérica hacia las comunidades de la diáspora sefaradí occidental durante el siglo XVII, tuvo lugar un fenómeno en dirección contraria. Individuos que habían residido en el seno de estas congregaciones, decidieron retornar, temporal o definitivamente, a España, Portugal o sus colonias. Algunos de estos fueron procesados por la Inquisición. En los documentos de sus procesos de fe se encuentran interesantes descripciones a partir de las cuales se puede reconstruir algunos aspectos sociales y religiosos de la vida judía en dichas comunidades de la diáspora sefaradí. El presente artículo recoge una selección de fuentes inquisitoriales a partir de las cuales se abordan aspectos sobre el rito de la circuncisión, la educación y la vida sinagogal, y el papel que estos jugaron en el proceso de socialización de los cristianos nuevos que retornaron al judaísmo.
\end{abstract}

Palabras Clave: Educación; sinagoga; circuncisión; sidur; rezos, Ámsterdam; Ferrara; Bayona; Liorna.

The Socialization of the Conversos in the Western Sephardic Diaspora Communities ACCORDING to Inquisitorial Sources.- At the same time as the 17th-century emigration from the Iberian Peninsula to the Western Sephardic Diaspora took place, the reverse process also occurred. Several individuals who had belonged to these communities decided to return, temporarily or permanently, to Spain, Portugal, or their colonies, and were imprisoned and tried by the Inquisition. Trial documents provide us with some insight into the social and religious life of these communities. Using inquisitorial sources,

* La investigación cuyos resultados se presentan en este artículo ha sido financiada por el Consejo Europeo de Investigación (ERC), bajo el Séptimo Programa Marco de la Unión Europea (FP7/2007-2013), acuerdo de subvención núm. 295352.

** morenogold@gmail.com 
this article discusses some aspects of the circumcision rite, education, and synagogue life in these communities and their function in socializing the New Christians who returned to Judaism.

KeYwords: Education; Synagogue; Circumcision; Siddur; Prayers; Amsterdam; Ferrara; Bayonne; Leghorn.

Cuando varias décadas atrás Rivkin afirmaba que «los documentos de la Inquisición no pueden servir de evidencia para la vida religiosa de los conversos, sino que estos son únicamente una fuente que muestra lo que la Inquisición quería que la gente creyera sobre los conversos» ${ }^{1}$, se refería, sin lugar a dudas, a los conversos que residían en los reinos de España y Portugal. Sin embargo, las fuentes inquisitoriales no solamente hacen referencia a la vida de los conversos en la Península Ibérica, sino que además incluyen documentos a partir de los cuales se puede reconstruir parte del proceso de socialización en las comunidades judías de la diáspora sefardí occidental durante los siglos XVI y XVII. No olvidemos que paralelamente a la llegada de los nuevos judíos a las comunidades en Europa occidental -algunas de las cuales fueron fundadas por estos ex-conversos-, tuvo lugar un fenómeno en dirección contraria. Individuos que se habían asentado o residieron -meses o años- en el seno de estas congregaciones, decidieron retornar, temporal o definitivamente, a los reinos ibéricos. Algunos de estos fueron detenidos y procesados por la Inquisición en España, Portugal o las colonias en América. La gran mayoría de estos individuos pasaron un proceso de socialización durante el período que residieron en ciudades como Ámsterdam, Ferrara, Liorna, Hamburgo, Londres, Bayona, y sus conocimientos sobre el judaísmo normativo superaba generalmente al de aquellos conversos que nunca salieron de los límites de España o Portugal, incluyendo a quienes observaban en secreto ciertas prácticas y ceremonias judías.

Cabe recordar en este contexto el ardiente debate que ha tenido lugar desde los albores de la investigación del fenómeno converso, en lo que se refiere a la fiabilidad de los documentos inquisitoriales y la pregunta

\footnotetext{
${ }^{1}$ E. Rivkin, «The Utilization of Non-Jewish Sources for the Reconstruction of Jewish History», JQR 48 (1957-1958) págs.183-203: 192-193. Véase también el artículo de este autor: «How Jewish were the New Christians?», en Hispania Judaica, eds. J. M. SolASole, S. G. Armistead y J. H. Silverman, vol. I (Barcelona 1980) págs 105-115.
} 
sobre la relevancia de dichas fuentes para la investigación histórica ${ }^{2}$. Los documentos de la Inquisición, minuciosos y detallados como suelen ser, ofrecen descripciones muy interesantes no solamente sobre las comunidades, sino también sobre la experiencia personal de quienes vivieron los procesos de llegada, adaptación, educación y participación en la vida religiosa y social en dichos contextos. A pesar de esto es fundamental tener presente la argumentación de Rivkin y otros autores que desacreditan la fiabilidad de las fuentes inquisitoriales y recordar que la Inquisición era un cuerpo represivo y que los testimonios presentados en dichos procesos fueron obtenidos bajo coerción física y psicológica. El Santo Tribunal perseguía la herejía, y el interés de los procesados era ocultar o intentar justificar cualquier práctica que lo pudiera incriminar. A consecuencia de ello es evidente que estos testimonios tienen que ser leídos críticamente y no toda la información que en ellos figura podrá ser aceptada automáticamente como prueba fidedigna de los hechos. Sin embargo, y justamente por lo anteriormente señalado, parte de los testimonios que serán mencionados en el presente artículo resultan particularmente asombrosos y convincentes: algunos de los reos no escatimaban en sus descripciones sobre

\footnotetext{
${ }^{2}$ Algunos de los principales estudios en los que se defienden la fiabilidad de las fuentes inquisitoriales: Y. H. Yerushalmi, From the Spanish Court to Italian Ghetto (SeattleLondon 1981) págs. 21-42; A. Domínguez OrTiz, Los judeoconversos en la España moderna (Madrid 1993) págs. 17-19 y 254-258; J. CARo BAROJA, Los judíos en la España moderna y contemporánea. Vol. I (Madrid 1996) págs. 13-21 y 453-506; I. S. RÈvAH, «Les Marranes», Revue des Études Juives, I (CxvIII) (1959-1960) págs. 3-77; H. BeInART, Conversos on Trial (Jerusalem 1981) págs. 48-87; J. P. Dedieu, «The Archives of the Holy Office of Toledo as a Source for Historical Anthropology», en The Inquisition in Early Modern Europe: Studies on Sources and Methods, eds. G. Henningsen, J. Tedeschi y Ch. Amiel (De Kalb 1986) págs. 158-171. En lo que respecta a las posturas que cuestionan el uso de dichas fuentes para la investigación histórica, vid. los artículos de E. RivkIN antes citados; R. GARCíA CÁRCEL, «¿Son creíbles las fuentes inquisitoriales?», en Grafías del imaginario: representaciones culturales en España y América (siglos XVI-XIII), eds. C. A. GónZÁlez-SÁnchez y E. Vila Vilar (México 2003) págs. 96-110: 103; B. Netanyahu, The Marranos of Spain - From the Late 14th to the Early 16th Century (New York 1966) págs. 1-4, y «¿Motivos o pretextos? La razón de la Inquisición», en Judios. Sefaraditas. Conversos, ed. A. Alcalá (Valladolid 1995) págs. 23-44; A. J. Saraiva, Inquisição e Cristãos-Novos (Lisboa 1985) págs. 39-55. Un interesante ejemplo de ambas posturas, defendidas por Rèvah y Saraiva, puede encontrarse en el apéndice añadido en la edición de 2001 (A. J. Saraiva, The Marrano Factory [Boston 2001], págs. 235-294). Véase un resume de la polémica y referencia a los diferentes estudios en D. M. Grtuitz, Secrecy and Deceit: The Religion of the Crypto-Jews (Philadelphia-Jerusalem 1996) págs. 76-90.
} 
su experiencia en las comunidades judías e incluían muchos detalles que no solamente no podían haber sido fabricados por los inquisidores, sino que además claramente los incriminaban en su «delito herético».

Antes de abordar propiamente la materia de nuestro artículo me permito hacer dos aclaraciones metodológicas: Primero, los documentos de la Inquisición que utilizaremos nos ofrecen retazos de información sobre diversas comunidades y en distintos períodos de tiempo. Por lo tanto, para poder sacar verdadero provecho de estos testimonios es imprescindible contextualizar cada uno de estos, tomando en consideración el tipo de comunidad que describen y el período concreto que reflejan. Aun así, y partiendo de la premisa que a pesar de sus diferencias, en las comunidades de la diáspora sefardí occidental se vivieron fenómenos similares, esperamos que el presente artículo ofrezca una visión horizontal sobre aspectos determinados de su proceso de socialización. Segundo, cabe también aclarar que los casos que nos ocupan -es decir, los testimonios de individuos que tras haber vivido en el marco de una de las comunidades judías de la diáspora española, regresaron a territorio español y fueron procesados por la Inquisición- fueron juzgados por distintos tribunales, en variados enclaves geográficos y en diferentes épocas. Para la elaboración del presente artículo se han utilizado los manuscritos de más de una docena de procesos de fe, así como también algunos procesos que fueron publicados en el pasado, en los cuales se encuentran alrededor de cincuenta testimonios presentados ante la Inquisición española. Sin embargo, no cabe la menor duda que la presente investigación no es exhaustiva y que en los archivos de la Inquisición española, así como la portuguesa, se pueden encontrar otros muchos casos relevantes. En este sentido, el presente artículo debe entenderse como un primer intento en un campo que aún está por explorar en mayor profundidad.

\section{LA LLEGADA A LAS COMUNIDADES JUDÍAS: RECEPCIÓN Y CIRCUNCISIÓN}

Según la tradición judía normativa, el berit milá, la circuncisión, es un rito que se lleva a cabo al octavo día del nacimiento de los niños varones. Los conversos que nacieron en los reinos españoles y portugueses, incluso quienes guardaban secretamente algunas de las tradiciones judías, en muy raras ocasiones llevaban a cabo esta ceremonia. La circuncisión se convirtió en el rito de iniciación central tras 
la llegada de los conversos a los marcos de las comunidades judías en occidente. Este hecho se ve reflejado en los numerosos testimonios sobre dicho rito que fueron recogidos en los archivos de la Inquisición. Evidentemente la circuncisión era una marca física que los procesados no podían ocultar ante las autoridades del Santo Oficio ${ }^{3}$; algunos reos afirman haber sido circuncidados y otros incluso describieron en detalle dicha ceremonia.

Tomemos el ejemplo de Baltazar Araujo quien vivió en Galicia hasta la edad de nueve o diez años y en 1596 abandonó la Península Ibérica junto a su familia siendo Venecia la primera comunidad judía a la que llegaron $^{4}$. En los siguientes términos se refiere Araujo a esta primera etapa en el seno de la comunidad judía: «Después de circuncidado le avía dado un librillo de los que se dan a los judíos principiantes para que aprendiesse las oraciones de la ley y fuesse a las sinagogas» ${ }^{5}$. Esta afirmación, corta y concisa, refleja en pocas palabras un amplio y complejo proceso. Ante todo, tuvo lugar el acto de la circuncisión. Llama la atención que Araujo no ofrezca mayor descripción de dicho rito sino que lo mencione sólo como el punto de partida. La circuncisión fue el principio, el punto que dio comienzo a su proceso de integración en la comunidad judía. Todo lo demás, vino después. En estas comunidades dicho acto era en cierto modo el «primer requisito» para poder integrarse en el nuevo contexto social. En efecto, es muy importante comprender el significado y la función social y religiosa que se le adjudicaba al rito de la circuncisión en estas comunidades.

\footnotetext{
${ }^{3}$ Aún así, hemos encontrado varios casos en los que los reos argumentaron para su defensa que la marca en su miembro viril se debía a enfermedades venéreas o de otro tipo; véase, por ejemplo, en el Proceso de Luis Gómez Barreto (Archivo Histórico Nacional - Inquisición [en adelante AHN-I], legajo 1620, expediente 18, folio 256v): «Dixo el susodicho que avría quinse meses que Diego Lópes Cabra cirujano le había cortado algunos pellejitos del prepucio por unas llagas que abía tenido».

${ }^{4}$ Sobre la congregación ponentina de Venecia en los siglos XVI-XVII, vid. R. BonfIL, «Los judíos españoles y portugueses en Italia», en El Legado de Sefarad, ed. H. BEINART (Jerusalén 1993) págs. 225-248: 230-236; B. Pullan, The Jews of Europe and the Inquisition of Venice 1550-1670 (Oxford 1983) págs. 229-312, y B. RAVID, «The Venetian Government and the Jews», en The Jews of Early Modern Venice, eds. R. C. DAvis y B. RAvID (Baltimore 2001) págs. 3-30.
}

${ }^{5}$ Proceso contra Luis Franco, AHN-I, leg. 1620, exp. 5, fol. 9v. 
Aunque no tenemos noticias concretas de reglamentación concernientes a la obligación de la circuncisión en el contexto de la comunidad ponentina de Venecia, conocemos este tipo de estatutos en otras comunidades de ex-conversos. La congregación Bet Israel, fundada en Ámsterdam en 1618, publicó una reglamentación en agosto de 1620 según la cual no podrían entrar a la sinagoga quienes no se hubieran circuncidado antes de Roš Hašaná (término hebreo para referirse al año nuevo. En dicho años el año nuevo hebreo correspondía a la noche del 27 de septiembre). Según Kaplan, es muy probable que las otras dos congregaciones sefardíes de Ámsterdam, fundadas con anterioridad, cuyos registros no se conservan, hayan implementado reglamentaciones similares ${ }^{6}$. Este testimonio de Araujo, que describe una época anterior a la reglamentación conocida en Ámsterdam, muestra que también en esta congregación el acto de la circuncisión se concebía socialmente como el primer paso y acaso requisito indispensable, para integrarse al judaísmo normativo.

Según explica Kaplan, dado que la llegada de cristianos nuevos a lugares donde existían comunidades judías no implicaba necesariamente su retorno al judaísmo, la primera época en la que entablaban contacto con los miembros de la comunidad judía era un paso liminal, anterior a su decisión de adoptar su nueva identidad. La circuncisión debía sacar al converso de su situación indefinida, y debía representar su aceptación definitiva de formar parte de la grey judía. Teniendo en cuenta que a partir de dicho momento su judaísmo quedaría sellado en su propio cuerpo, es de suponer que su inclinación a abandonar el judaísmo o regresar a tierras donde podría ser perseguido por la Inquisición disminuiría significativamente ${ }^{7}$. El rito de la circuncisión en el proceso de retorno al judaísmo, sin embargo, no puede ser entendido exclusivamente como un medio para intentar prevenir su regreso a las tierras de idolatría. Tomemos en consideración que los conversos que retornaron al judaísmo vivieron una circunstancia histórica esencialmente diferente a la del general de los judíos tradicionales. Estos conversos habían nacido en el seno de familias

${ }^{6}$ Y. KAPLAN «'El primer y más importante precepto' - La circuncisión en mundo de los conversos que regresaron al judaísmo a principios de la Edad Moderna» [en hebreo], en From Sages to Savants, eds. J.R. Hacker, Y. Kaplan y B.Z. Kedar (Jerusalem 2010) págs. 353-389: 358.

${ }^{7}$ Y. KAPLAN, «'El primer y más importante precepto’...», pág. 367. 
cristiano-nuevas, y por lo tanto la circuncisión tenía lugar en muchos casos a edad adulta y como fruto de una decisión personal (generalmente al integrarse a una comunidad judía fuera de la Península Ibérica). En estas circunstancias puede entenderse la razón por la que este rito llegó a ocupar un lugar de primera importancia en su visión religiosa. Entre los conversos y aquellos que regresaron al judaísmo, el acto de la circuncisión adquirió un valor similar al del sacramento cristiano del bautismo. La circuncisión se convirtió en la principal seña de judaísmo y requisito indispensable para la redención del alma, tal como se refleja en la afirmación de Juan Pacheco de León ante los inquisidores en México: «Lo mismo es entre los judíos la circuncisión que el bautismo es entre los cristianos» ${ }^{8}$.

También en el caso de Méndez Chávez, en la comunidad de Ámsterdam, encontramos una descripción muy similar. Tras haber tomado la decisión de adoptar el judaísmo, el primer paso fue la circuncisión, acto después del cual le fue entregado oficialmente su primer libro de rezos:

[...] con lo qual, trajeron a su cassa un ravi que no se acuerda como se llamava y se sentó uno de dichos judíos en una silla y este se sentó en sus muslos, teniéndolo el dicho judío, y sobre el sombrero le pucieron un $\mathrm{p}$ [a] ño blanco por ceremonia de aquel acto. Y el dicho rabi cantó un psalmo y luego con unas tijeras cortó a este una parte del prepucio, y le curo con un poco de aseite - y le dieron un libro impreso en lengua castellana y hebraica de lo que abía de leer y hazer aunque este no sabía leer lo hebraico ${ }^{9}$.

De los testimonios recibidos ante los tribunales de la Inquisición queda claro que en altos porcentajes, aquellos hombres que pasaron al menos un tiempo considerable en alguna de las comunidades judías de Occidente fueron circuncidados. Esto puede determinarse a partir de los exámenes físicos a los que debían someterse los reos, así como también los testimonios de los procesados que describen dicho ritual ${ }^{10}$.

Resulta interesante analizar el papel que jugó el rito de la circuncisión en el caso francés, pero antes es fundamental dejar en claro la peculiaridad del caso francés. Ante todo debe tenerse en cuenta la cercanía física

\footnotetext{
${ }^{8}$ Citado en Y. KaPLAN, «'El primer y más importante precepto' ...», pág. 375.

${ }^{9}$ Proceso contra Luis Méndez Chávez, AHN-I, leg. 1620, exp. 9, fol. 35r.

${ }^{10}$ Véase otro ejemplo de una circuncisión llevada a cabo en Ámsterdam en el Proceso contra Miguel Arias del Valle, AHN-I, leg. 1621, exp. 11, fols. 86v-87v.
} 
entre la Península Ibérica y el sur de Francia, hecho que sin lugar a dudas facilitaba y fue una de las causas inmediatas de los movimientos migratorios desde España y Portugal a dicha región. Además no debemos olvidar que, a diferencia de las comunidades de la diáspora sefardí occidental antes mencionadas, durante el siglo XVII e incluso las primeras décadas del XVIII, los grupos de cristianos nuevos que residían en Francia se encontraban aún en una situación ambigua. Desde la época del rey Enrique II, a partir de 1550 fueron otorgadas varias Cartas Patentes a los cristianos nuevos ibéricos, en las cuales se les garantizaban el establecimiento seguro en territorio francés; se fijaban condiciones económicas favorables, y se les ofrecía protección para evitar persecuciones religiosas ${ }^{11}$. Además, y a pesar del rigor de la profesión de la religión católica, en Francia no funcionaban tribunales inquisitoriales. Durante el siglo XVII, aunque no contaban con autorización oficial de crear comunidades judías ni de practicar pública y abiertamente sus ritos, muchos conversos conservaron tradiciones criptojudías (y mantuvieron contacto con comunidades judías principalmente con la de Ámsterdam ${ }^{12}$ ) de forma más amplia y se comenzaron a organizar discretamente como comunidades religiosas criptojudías, siendo este hecho de conocimiento público. Esta realidad en la Francia del siglo XVII en la que por un lado el judaísmo aún no era una religión oficialmente permitida, y por el otro las prácticas criptojudías eran comunes y conocidas por el general de la población, se ve reflejada en el siguiente testimonio recibido en la Inquisición de Toledo: «[...] que esto [el rito de la circuncisión] se habla con poco recato en Bayona por no haber Inq[uisici]ón ni recelo de castigo que por acá se hace"”» ${ }^{13}$.

Fue tan sólo en el siglo XVIII cuando las comunidades judías recibieron reconocimiento y autorización oficial. El texto más importante fue el de las Cartas Patentes de Luis XV que se otorgaron en Meudon en 1723,

${ }^{11}$ A. ZINK, «Une niche juridique. L'installation des Juifs à Saint-Esprit-lès Bayonne au XVII ${ }^{\mathrm{e}}$ siècle», Annales. Histoire, Sciences Sociales 49:3 (1994) págs. 639-669: 640-641 у 643-644.

${ }^{12}$ Vid. G. Nahon, Métropoles et Périphéries Sefarades D’Occident (Paris 1993) págs. 112-114; Y. KAPLAN, «El lugar del Rabino Moisés Rafael de Aguilar en su relación con los exiliados españoles y portugueses del siglo XVII», Sexto congreso mundial de ciencias judaicas (Jerusalén 1973 [en hebreo]) págs. 95-106: 97-98.

${ }^{13}$ Proceso contra Diego Rodríguez Cardozo, AHN-I, leg. 177, exp. 11, fol. 49r-v. 
en las que se oficializaba la religión de los interesados de una forma extraordinaria ${ }^{14}$.

Durante el siglo XVII, cuando los conversos se encontraban en la situación limítrofe antes mencionada, el acto de la circuncisión, así como la función que este jugaba en el proceso de socialización, fue diferente al de las comunidades judías ya constituidas. Tal como se ha expuesto en los ejemplos antes citados, cuando un converso llegaba a una comunidad judía, lo primero que se esperaba de él era que se sometiera a la circuncisión. En contraste, podemos observar que dadas las circunstancias en Francia este rito no constituía el primer requisito para adherirse al grupo criptojudío organizado. Por el contrario, los testimonios sobre el rito de la circuncisión en el caso francés durante el siglo XVII, más que demostrar que se tratase de una exigencia para la incursión de nuevos miembros, reflejan el interesante y paulatino proceso de consolidación de la comunidad religiosa, así como la interacción y la relación que existió entre los grupos de conversos en Francia y otras comunidades judías de Occidente, principalmente la de Ámsterdam.

Es curioso que justamente Graizbord, quien abordó exhaustivamente el caso francés, se refiera al acto de la circuncisión, como medio para imponer el orden y la disciplina en la comunidad judía ${ }^{15}$ ¿ ¿Acaso la comunidad criptojudía de Francia contaba con la capacidad para imponer disciplina cuando aún se carecía de la infraestructura y la autoridad para ello? Tal como lo señala Nahon, los primeros reglamentos del gobierno interno de las comunidades francesas de los que se tiene noticias se remontan a mediados del siglo XVIII ${ }^{16}$ : la codificación de Bayona (1752) y la de Burdeos $(1760)^{17}$. Además, tal como el propio Graizbord expone de modo

${ }^{14}$ Vid. G. NAhon, Juifs et Judaïsme À Bordeaux (Pamplona 2003) págs. 61-73, y «El judaísmo sefardí en Francia: de cristianos nuevos a miembros de la Nación judeoportuguesa de Francia» en Moreset Sefarad: El legado de Sefarad. Vol. II, ed. H. BeInarT (Jerusalén 1993) págs. 348-376: 348-350.

${ }^{15}$ D. L. GraizBord, «Becoming Jewish in Early Modern France: Documents on Jewish Community-Building in Seventeenth-Century Bayonne and Peyrehorade», Journal of Social History 40:1 (2006) págs. 147-180: 156.

${ }^{16}$ Existen indicios de la existencia de estatutos incluso anteriores, vid. NAHON, Juifs et Judaïsme, págs. 61-73.

${ }^{17}$ NAHON, «El judaísmo sefardí en Francia...», págs. 360-361. Véase también: S. Schwarzfuchs (ed.), Le registre des deliberations de la nation juive portugaise de Bordeaux (1711-1787) (Paris 1981). 
claro y contundente, no en todo momento a lo largo del siglo XVII existía la posibilidad de realizar la circuncisión, especialmente tomando en consideración que en dichas ciudades no había mohel de planta, sino que esporádicamente venían hombres capacitados, y por períodos de tiempo limitados, para realizar el rito de la circuncisión a quien lo deseara. Por ejemplo, en el caso de Bayona, se tiene noticias de un mohel holandés llamado Jacob Chamis ${ }^{18}$ (o Xamis) de Orta, alias «Moyses Que» ${ }^{19}$ (Moisés Cohen), que circuncidó a muchos hombres en Saint-Esprit, Peyrehorade y Burdeos a finales de los años 50, tal como se puede apreciar en un testimonio del proceso de fe contra Diego Rodríguez Cardozo ${ }^{20}$. En los años 60, un expatriado proveniente de Liorna o Ámsterdam llamado Abraham ben Israel $^{21}$ sirvió como mohel en Saint Esprit. En la segunda mitad del siglo XVII fue contratado en Bayona Isaac de Ávila ${ }^{22}$, quien se instaló en la ciudad y cuyas funciones eran leer la Biblia, predicar el judaísmo y realizar la circuncisión ${ }^{23}$.

${ }^{18}$ En los registros de la Inquisición de Toledo se tiene noticias sobre este mohel; vid. Proceso contra Diego Rodríguez Cardozo, fol. 172r.

${ }^{19}$ Vid. D. Willemse (intr. \& trans.), Un "Portugués" entre los castellanos - El primer proceso inquisitorial contra Gonzalo Báez de Paiba 1654-1657 (Paris 1974) pág. LV, nota 77.

${ }^{20}$ Proceso contra Diego Rodríguez Cardozo, AHN-I, leg. 177, exp. 11, fol. 49r-v. No está del todo claro si se trata de otra persona, o si Francisco López era el mismo Jacobo Chamis.

${ }^{21}$ Véase la declaración de Antonio Rodríguez de Amezquita ante la Inquisición de Toledo en 1665 en el Proceso contra Diego Rodríguez Cardozo, fol. 222v.

${ }^{22}$ Sobre la figura de Isaac de Ávila nos llegan noticias a partir de distintas fuentes. Por un lado, este personaje es mencionado en varias ocasiones en los testimonios ante la Inquisición. Por el otro lado, Aguilar también hace referencia a Ávila en una pregunta que le fue dirigida a Ámsterdam desde Bayona, tal como lo menciona KAPLAN («El lugar del Rabino Moisés Rafael...», págs. 99-101). Más adelante haremos referencia al episodio descrito en este artículo. Para más información sobre Isaac de Ávila, vid. G. NAHON, «Terre D'Idolâtrie:: Isaac-Israel de Ávila, Hayyim-Isaac de Mercado, Abraham Vaez, Rabbins À Bayonne au XVII Siècle», Roumanie, Israël, France: parcours juifs (Paris 2014) págs. 145-186: 154-155.

${ }^{23}$ Graizbord («Becoming Jewish in Early Modern France...», pág. 155) señala que estas fueron las funciones oficiales de Ávila, basándose en el testimonio de Juan Ibáñez ante la Inquisición. Nahon señala que no se sabe con certeza si existió un contrato escrito que definiera las funciones de Ávila en Bayona. De cualquier forma, a pesar de la presencia de Ávila, durante las últimas décadas del siglo XVII volvemos a tener noticias de un mohel itinerante: el rabino Abraham ben Levi Conque de la Yešibá de Hebrón. 
En la Bayona de los años 50 del siglo XVII, la circuncisión no era un acto impositivo, sino más bien voluntario, y sin lugar a dudas, no constituía el primer paso en el proceso de socialización de la comunidad religiosa. Veamos por ejemplo la declaración que ofrece Manuel Fernández Rodríguez ante la Inquisición de Cuenca en mayo de 1659 sobre lo que posiblemente fueron las primeras circuncisiones rituales ${ }^{24}$ en Bayona:

Diego Rodríguez Cardoso hauía mandado traer a Bayona, a por su quenta desde Flandes, a un cirujano para que circuncidase a todos los que quisiesen y fuesen observantes de la dicha ley; porque para sí y su padre le auía mandado venir y que así era buena ocasión para todos lo que quisiesen. Y algunos días después, el mismo cirujano flamenco le dijo a este que por que no se quería sentar en su libro y circuncidarse. Que así le traería Dios acarrera de salvar y no saue decir de que nación era, mas de que el decía que era de Olanda ${ }^{25}$.

Antes de realizar la circuncisión, un grupo significativo de individuos se reunía para realizar rezos, contaban con libros de oraciones ${ }^{26}$ y practicaban diferentes ritos. Dando un paso adicional, Diego Rodríguez Cardoso, uno de los líderes de la congregación que se comenzaba a perfilar, y un prominente comerciante ${ }^{27}$, mandó a traer por su cuenta de Ámsterdam a un mohel. Una vez en el lugar, el mohel intentó persuadir a otros individuos para que aprovecharan la oportunidad y se circuncidaran, y en efecto algunos lo hicieron. Sin embargo, con esta visita no se impuso, ni se disciplinó o se castigó a ninguno de los conversos que no hubieran op-

${ }^{24}$ Véase otras descripciones detalladas sobre el rito de la circuncisión en Francia en los años 50 y 60 en el Proceso contra Fernando Medina, fol. 33r-v, y en el Proceso contra Diego Rodríguez Cardozo, fols. 222v-223v.

${ }^{25}$ Proceso contra Diego Rodríguez Cardozo, fols. 91v-92v.

${ }^{26}$ Sobre la función de los libros impresos en el proceso de socialización de las congregaciones criptojudías en Francia, vid. C. WILKE, «Un judaïsme clandestin dans la France du XVIIe siècle : un rite au rythme de l'imprimerie», en Transmission et passages en monde juif, ed. E. Benbassa (Paris 1997) págs. 281-311.

${ }^{27}$ Sobre Diego Rodríguez Cardoso, vid. J. Caro Baroja, Los judíos en la España moderna y contemporánea. Vol. II (Madrid 1986) págs. 145-159; Y. KaPLAN, «Cristóbal Méndez alias Abraham Franco de Silveyra: las aventuras de un converso del siglo XVII» [en hebreo], en Studies in Jewish History presented to Yosef Haker, eds. Y. Ben NaEH, J. Cohen, M. Idel and Y. Kaplan (Jerusalem 2013) págs. 406-440: 424, y NAHON, «El judaísmo sefardí en Francia...», pág. 355. 
tado por tomar este paso. En todo caso, si bien es cierto que la posibilidad de imponer disciplina en las congregaciones de Francia era mucho más complicada, no faltaron los intentos de presionar por otros medios a los miembros de estas congregaciones para que se sometieran a la circuncisión. Un ejemplo de esto fue la carta falsificada que difundió Ávila entre los cristianos nuevos de Bayona, presuntamente firmada por los rabinos Isaac Aboab, David D’Aguilar y Moisés Mans, en la cual se advertía que sólo los circuncisos podrían gozar de la salvación del alma ${ }^{28}$.

Cabe señalar también que en este período de transición, estas familias aún se veían obligadas a recibir el bautismo ${ }^{29}$. Casos casi simbólicos de la situación ambigua que se vivía en Francia en aquella época son los de aquellos que pasaron por ambos ritos de iniciación religiosa, tal como queda registrado en las declaraciones de Fernando Medina ante la Inquisición de México:

Dijo que es x[ris]ptiano baptizado en dicha villa de Peñaorada, según supo y tiene por cierto, aunque el baptismo fue siendo niño; porque por aquel tiempo no se permitía a los judíos en aquella provincia, el que dejasen de baptizar a sus hijos en la ley catholica [...] declara, que es precepto de la ley, circuncidarse los hombres, y este lo está y se acuerda le circuncidaron, de edad de seis, o, siete años ${ }^{30}$.

A pesar de las diferencias mencionadas respecto al papel que jugó el rito de la circuncisión en las comunidades religiosas de Francia durante el siglo XVII, y las comunidades judías ya establecidas oficialmente en la misma

${ }^{28}$ Kaplan, «El lugar del Rabino Moisés Rafael...», p. 99. Véase también: Y. Kaplan, «Wayward New Christians and Stubborn New Jews: The Shaping of a Jewish Identity», Jewish History 8:1-2 (1994) págs. 27-41: 31-33; NAHON, «El judaísmo sefardí en Francia...», págs. 155-156. Compárese con lo que escribe Menasseh Ben Israel: «[...] Pello que aquelle que anulla o firmamẽto de Abraham nosso pay, pasto que tenah outras boas obras, naõ tem parte no outro mundo» en Thesouro Dos Dinim - Ultima Parte (V), Da Circuncição, Cap. I: 3 (Amsterdam 1646) pág. 140.

${ }^{29}$ Vid. A. Zink, «Être juif à Bayonne en 1630», Annales du Midi: revue archéologique, historique et philologique de la France méridionale, vol. 108, núm. 216 (1996) págs. 441460: 442, y «Une niche juridique...», págs. 661-662. Además, tal como lo señala NAHON («El judaísmo sefardí en Francia...», pág. 354), los portugueses guardaban las apariencias en lo que respecta al catolicismo, no solamente en lo que respecta al bautismo: «Inscribían en los registros parroquiales los bautizos, las bodas y las defunciones».

${ }^{30}$ Proceso contra Fernando Medina, AHN-I, leg. 1733, exp. 16, fols. 29v-33r. 
época, no cabe duda de que también en el caso francés este rito fue practicado y ocupó un lugar de importancia en los procesos de socialización que tuvieron lugar en este contexto. Si bien no fue un acto impuesto bajo pena de sanción alguna, este rito, adquiría un significado similar al que se le adjudicaba en otros enclaves de la diáspora sefardí, en cuanto a que representaba la expresión máxima e irreversible del compromiso con el judaísmo.

En las comunidades judías de la diáspora sefardí del siglo XVII, el acto de la circuncisión era un evento de gran importancia que incluía tanto aspectos religiosos como sociales. Tal como se puede apreciar en la siguiente declaración de Miguel Arias del Valle, quien llegó a Ámsterdam en los años 60 del siglo XVII, la circuncisión y los días de recuperación que conllevaba, eran una especie de presentación en sociedad. Después de la circuncisión, se les daba la bienvenida en la sinagoga, y además se les tributaba un cálido recibimiento, puesto de manifiesto con las visitas que el nuevo miembro atendía, incluso por parte de otros comunitarios que hasta el momento no conocía:

Que dos o tres días después de circuncidado, entre otras personas que llegaron a ver el auto en la ciudad de Absterdan, fueron dos mugeres. Y la una de ella, no sabe cómo se llama, le preguntó que si conocía en Sevilla a don Simon Rodrígues Cardoso. Y este respondió que sí le conocía porque en tiempos del administrador general don Luis Moreno Ponce de León avía tenido el arrendamento del tavaco de Sevilla y su Reynado, a que dicha muger le respondió que era su hermano, y que quánto tiempo hacía que este le avía visto y si estaba bueno. Y este le respondió que abría más de un año que le avía visto en dicha ciudad de Sevilla y que quedaba bueno. Y que la dicha muger le dixo a este que le preguntaba, porque avía siete y ocho correos que no sabía del $^{31}$.

Este episodio ejemplifica además la dinámica de las relaciones y de las comunicaciones entre conversos y judíos, en distintos enclaves del mundo. Esta mujer, que vivía abiertamente su judaísmo en Ámsterdam, conservaba sus vínculos con un hermano que vivía como cristiano en España. Sospechaba que la llegada de un converso procedente de Sevilla podría brindarle la posibilidad de recibir noticias suyas y, en efecto, no se equivocaba.

\footnotetext{
${ }^{31}$ Proceso contra Miguel Arias del Valle, AHN-I, leg. 1621, exp.11, fol. 75r-v.
} 


\section{EDUCACIÓN FORMAL}

Entre los testimonios presentados ante los tribunales inquisitoriales se puede encontrar también fuentes relevantes que ilustran sobre la reeducación de los marranos -por utilizar la formulación de Yerushalmi ${ }^{32}-\mathrm{y}$ su función en el proceso de socialización de los inmigrantes provenientes de la Península Ibérica.

Tal como intentaremos demostrar, el tipo de educación judía que recibieron estos individuos no fue idéntico en todos los casos y dependió en gran medida de dos factores: 1) la edad en la que el individuo se integró a la comunidad judía; 2) el tipo de comunidad a la que llegó (es decir, si se trataba de una comunidad judía ya establecida o una congregación en proceso de consolidación).

Antes de abordar el tema de la educación formal de los inmigrantes conversos tras su llegada a las comunidades judías, cabe señalar que en muchos casos el proceso de instrucción en lo referente al judaísmo se iniciaba antes de su incursión en dichas congregaciones. Cuando nos referimos a la formación de estos individuos, es importante tomar en consideración esta etapa previa a la emigración, no necesariamente por la cantidad o la exactitud de contenidos aprendidos -en ocasiones precarios-, sino principalmente por el papel central que estos jugaron en sus complejos procesos de identidad.

Retomemos el caso de Baltazar Araujo, antes mencionado. Su proceso de iniciación y de educación se puede trazar de forma clara y coherente, y en él se distinguen distintas etapas. Su primer contacto con la tradición judía tuvo lugar aún en tierras hispánicas. Al referirse a sus estudios y retorno al judaísmo normativo, Araujo deja claro el papel central y decisivo que tuvo su madre:

Si bien, desde que avían tomado puerto en Flandes por donde avían hecho su viaje, le avía començado la dicha su madre a catequiçar en la dicha ley de Moysén, y aún en la dicha Villa de Bayona su tierra le avía hecho ayunar el día grande que llaman Equipur [...] y que luego [en Venecia], le

${ }^{32}$ Y. H. Yerushalmi, «The Re-Education of the Marranos in the Seventeenth Century», The Third Annual Rabbi Louis Feinberg Memorial Lecture in Judaic Studies (Cincinnati 1980). 
avía puesto la dicha su madre a la de la escuela de un Rabi mulato ${ }^{33}$, hombre muy entendido en la ley, que era el que le avía circuncidado y le avía puesto por nombre Abraham Senior ${ }^{34}$.

Es de suponer que el proceso de socialización a edad temprana tenía varias ventajas en lo que se refiere a la disponibilidad del individuo para aprender, interiorizar los nuevos conceptos y valores y, finalmente, adaptarse al distinto contexto socio-religioso; pero ni siquiera la educación a edad temprana constituía un seguro ${ }^{35}$.

Todo parece indicar que este comienzo de la relación entre el joven Araujo y el criptojudaísmo fue una experiencia corta y limitada. El acusado mencionó que su madre lo hizo ayunar «el día grande que llaman Equipur», pero no podemos saber con seguridad si en el marco familiar no se realizaron otros rituales criptojudíos. Aparentemente, mientras vivían en el contexto hispánico la práctica ritual era esporádica y no una cuestión diaria o rutinaria -o al menos eso era lo que Araujo intentaba argumentar ante el Santo Oficio.

La segunda etapa en el proceso de la educación judía del joven Araujo comenzó durante su travesía, después de dejar España. Tal como lo afirma Yerushalmi, «the flight was itself already an act of intense Jewish commitment, not to be undertaken easily or capriciously» ${ }^{36}$; de hecho, fue este autor el primero en señalar la importancia de la etapa anterior a la llegada a las comunidades como parte integral del procesos de retorno de los cristianos nuevos al seno del judaísmo normativo ${ }^{37}$. En este caso, la fuerza de este compromiso se manifiesta en la actitud de

${ }^{33}$ Posiblemente se trataba de un rabino llegado del norte de África de tez morena. No se ha logrado identificar a quién se refería exactamente.

${ }^{34}$ Proceso contra Luis Franco, fol. 9v.

${ }^{35}$ El propio Araujo regresó al reino español y se instaló en la ciudad de Santa $\mathrm{Fe}$ de Antioquía en el Nuevo Reino de Granada. Si bien a lo largo de su proceso, y como veremos más adelante, demuestra poseer conocimientos sobre el judaísmo normativo, todo parece indicar que en este caso, tras su retorno a las tierras españolas, no conservó creencias o costumbres critpojudías.

${ }^{36}$ Y. H. Yerushalmi, «The Re-Education of the Marranos in the Seventeenth Century...», pág. 2.

${ }^{37}$ Y. H. Yerushalmi, «Marranos Returning to Judaism in the Seventeenth Century: Their Jewish Knowledge and Psychological Readiness», en Proceedings of the Fifth World Congress of Jewish Studies, 1969 (Jerusalem 1972 [en hebreo]), vol. II, págs. 201-209. 
la madre quien, en cuanto tuvo la oportunidad, comenzó de inmediato y sin ninguna espera a enseñarles a sus hijos, ya sin tapujos ni miedo, lo poco que ella sabía sobre la fe y la tradición judía. Evidentemente sus conocimientos eran escasos, por lo que al llegar a Venecia puso a Baltazar (y probablemente a sus otros jóvenes hermanos) en manos de un maestro judío capacitado.

Con la llegada de la familia a la ciudad de Venecia comenzó la siguiente etapa de la educación judía de Araujo. El paso del entorno familiar al entorno institucional significó para él un gran cambio en el proceso de adaptación al judaísmo normativo. Ya no se trataba de la intimidad y la complicidad familiar, sino de un inmenso mundo de conocimientos y vivencias, que abarcaba un lugar mucho más amplio en la vida rutinaria y que era enseñado por una persona conocedora, especializada y capacitada para ello.

La edad en la que un judeoconverso llegaba a la comunidad judía determinaba si el individuo habría de integrarse en un marco de educación formal o no, ya que en estas comunidades no se desarrollaron escuelas formales para la instrucción de adultos, sino que su proceso de aprendizaje y socialización se llevaba a cabo en otros lugares, principalmente en la sinagoga, tal como veremos más adelante.

Sin ser una excepción en comparación con el mundo judío normativo de otras zonas geográficas de Europa, también en estas comunidades los marcos de educación formal básica estaban dirigidos a niños desde los 4-6 años a los 13-16 años aproximadamente. Diego Díaz Nieto, que había nacido en Ferrara a finales del siglo XVI, adonde llegaron varios exiliados, principalmente desde Portugal durante el siglo $\mathrm{XVI}^{38}$, presentó ante la Inquisición de México una interesante descripción sobre la educación judía formal en dicha comunidad:

Y éste [Diego Díaz Nieto], de la dicha edad [seis o siete años], iba a la escuela de un maestro judío llamado Mose Cohén, que en romance quiere

${ }^{38}$ Vid. E. Horowitz, «Jewish Confraternal Piety in Sixteenth-Century and Ferrara: Continuity and Change» en The Politics of Ritual Kinship - Confraternities and Social Order in Early Modern Italy, ed. N. Terpatra (Cambridge 2000) págs. 150-171. A. DI Leone Leoni, La Nazione Ebraica Spagnola e Portoghese di Ferrara (1492-1559). Vol I (Firenze 2010) págs. 23-34. 
decir sacerdote, el cual le enseñó el alfabeto hebreo, que es el abecedario, y la lengua hebrea pronunciándola la dicha lengua hebrea en portugués, castellano e italiano, a donde estuvo hasta la edad de diez y seis años. Y en el dicho tiempo también acudía a tomar lección a la casa de una mujer viuda llamada Sara, que también enseñaba a muchachos ${ }^{39}$.

Justamente en el proceso contra Diego Díaz Nieto se encuentran documentos poco comunes que además nos ofrecen testimonios muy ilustrativos sobre los ámbitos de la educación formal en Ferrara. De modo sorprendente, en dicho proceso se solicitaron evidencias directamente desde dicha ciudad italiana. En efecto los registros de los interrogatorios llevados a cabo en Italia, fueron enviados posteriormente al tribunal en México. Es así como este proceso inquisitorial permite oír la voz de varios individuos judíos que vivían en dicha comunidad. Entre los testimonios llegados desde Ferrara se encuentra el de Moysén Carabon ${ }^{40}$. A pesar de haber pequeñas diferencias entre los dos testimonios ${ }^{41}$, la declaración recibida en Ferrara corrobora aquella obtenida en México, incluyendo algunos detalles adicionales. Según estos podemos concluir que Diego Díaz, junto a otros niños, recibió su formación básica por parte de una mujer viuda llamada Sara. Cabe destacar que esta no era una excepción, sino que, por el contrario, tal como señala T. Brener, en varias comunidades judías de Italia durante la temprana Edad Moderna, incluyendo la de Ferrara, la actividad de maestras judías era un fenómeno aceptado y difundido $^{42}$. Gracias a estos documentos sabemos que la educación formal de aquella ciudad contaba con distintos marcos (maestros) según las edades y el nivel de los alumnos. El maestro que enseñaba a niños y

39 «Segundo Proceso de Diego Díaz Nieto», transcrito en E. A. Uchmany, La vida entre el judaísmo y el cristianismo en la Nueva España 1580-1606 (México 1992) pág. 257.

40 «Segundo proceso de Diego Díaz Nieto», en Uchmany, La vida entre el judaísmo y el cristianismo, págs. 401-402.

${ }^{41}$ Por ejemplo, el nombre personal del maestro; pues según Diego Díaz se llamaba Mosé Cohen y según Moysén Carabón, Salomón Cohen.

${ }^{42}$ T. Brener («Teaching the Alef-Bet: Women Teach at Talmud Torahs in Italy» [en hebreo], Masejet 4 [2005] págs. 11-33: nota 6) basa su investigación en documentos protocolarios de las comunidades judías de Módena, Ferrara y Mantua de los siglos XVIIIXIX, aunque asume que estos protocolos reflejan una realidad que se remontaba a siglos anteriores. Evidentemente las fuentes aquí citadas corroboran esta estimación. 
adolecentes desempeñaba también el cargo de hazán, o cantor ritual, en la sinagoga levantina ${ }^{43}$. En cuanto a los contenidos de estudio, Diego Díaz Nieto ofrece la siguiente descripción:

Dijo que lo primero que les enseñan es el alfabeto hebreo y la oración de la Shema, que es muy larga. Y después de saber hebreo les enseñan caldeo $^{44}$, por curiosidad. Pero lo que es la lengua hebrea no hay ninguno que haya nacido en Ferrara, siendo judío, que no la sepa [...] que la lengua portuguesa la aprendió de oírla hablar al dicho Ruy Díaz [su padre] y a los de su casa y a otros muchos portugueses. Y no más ni menos aprendió la italiana y la castellana porque las dichas lenguas no se enseñan en las escuelas sino de oírlas hablar. Y después que éste estuvo en España y está en esta tierra habla bien la lengua castellana porque en Ferrara es tosca ${ }^{45}$.

En su descripción, Díaz Nieto pone énfasis en la cuestión de los idiomas, pero en realidad estos son un indicio de los contenidos que se enseñaban. Después de aprender a leer (y quizás a escribir) en caracteres hebreos, se dedicaban a la enseñanza de los rezos y la liturgia, que instruía a los alumnos para su participar activa en los rituales sinagogales. Al mencionar la legua caldea se está refiriendo al arameo: idioma que seguramente no era enseñado como un fin en sí mismo, sino como medio para poder estudiar textos talmúdicos y la tradición rabínica y, en efecto, este reo demuestra a lo largo de su proceso amplios conocimientos de la tradición rabínica. Esta breve descripción refleja que, en términos genera-

${ }^{43}$ Cabe aclarar que aunque el término «levantino» se refiere a los inmigrantes que llegaron a Italia desde el Imperio Otomano, en este contexto específico incluía también a los inmigrantes portugueses, tal como lo aclara en su declaración Yossepe Franco: «[...] a la escuela de los hebreos levantinos, que en otros tiempos se llamaba de los portugueses, aunque se fundó por los levantinos que son más antiguos en Ferrara que los portugueses»; vid. «Segundo proceso de Diego Díaz Nieto», en Uchmany, La vida entre el judaísmo y el cristianismo, pág. 397.

${ }^{44}$ Esto es, arameo, que es el idioma del Talmud, texto principal de la Ley Oral y la tradición rabínica judía. Este era el texto fundamental que se estudiaba en las casas de estudio y las academias de las comunidades judías tradicionales. Véase una interesante reseña sobre las academias de estudio en perspectiva histórica: M. BREUER, «Some Chapters of Jewish History as Reflected in the History of Yeshivot», en Education and History - Cultural and Political Contexts, eds. R. Feldhay y I. EtKes (Jerusalem 1999 [en hebreo]) págs. 181-197.

45 «Segundo proceso de Diego Díaz Nieto», en Uchmany, La vida entre el judaísmo y el cristianismo, págs. 314-315. 
les, la infraestructura de los contenidos de estudios formales en Ferrara no difería de modo sustancial de aquellos que se enseñaban en otras comunidades normativas judías de la época. Quizás lo que más llama la atención de esta descripción es el silencio absoluto en lo referente al estudio del texto bíblico. Sin embargo, una lectura de los procesos de Díaz Nieto no deja duda que había estudiado y que conocía en gran medida dicho texto. En audiencia del 10 de enero de 1601, pidió Diego Díaz una Biblia en hebreo, para poder presentar sus dudas, argumentando que no sabía latín ${ }^{46}$. Esta solicitud nos enseña que poseía ricos conocimientos de la lengua hebrea, y que estaba familiarizado con el texto bíblico.

Los documentos inquisitoriales nos ofrecen otro interesante testimonio que nos habla de otra comunidad en Italia: la de Liorna. Sin embargo, a diferencia de las comunidades de Ferrara y de Venecia, las cuales ya contaban con una tradición e infraestructuras anteriores a la llegada de los inmigrantes portugueses y españoles de los siglos XVI-XVII, la de Liorna era una comunidad mucho más joven, fundada y consolidada por dichos inmigrantes ${ }^{47}$. Por lo tanto no han de sorprendernos las diferencias entre esta comunidad italiana y las anteriores antes mencionadas. He aquí la descripción que ofrece Juan de León ante la Inquisición de México en los años 40 del siglo XVII:

Que siendo de edad de dos años lo llevaron sus padres a la ciudad de Liorna, del estado del Gran Duque de Florencia, donde lo criaron y eran vecinos, y observantes de la Ley de Moisés, la cual le enseñaron desde edad de cuatro años, y enviándolo a la escuela de los hebreos para que allí aprendiese la lengua hebraica y las oraciones de la dicha Ley, porque había tres escuelas de tres rabíes que la enseñaban, que el uno se llamaba Jacob y otro Abraham y otro que no se acuerda como se llama, y aunque iba a la dicha escuela nunca la prendió de buena voluntad, y le costaba

${ }^{46}$ «Segundo proceso de Diego Díaz Nieto», en Uchmany, La vida entre el judaísmo y el cristianismo, pág. 252.

${ }^{47}$ Vid. F. Aghib Levi D' ancona, «The Sephardi Community of Leghorn (Livorno)» en The Sephardi Heritage, ed. R. Barnett (London 1989) págs. 180-202; F. Trivellato, The Familiarity of Strangers - The Sephardic Diaspora, Livorno, and Cross-Cultural Trade in the Early Modern Period (New Haven-London 2009) págs. 43-58; C. FerRara DEGLI UBERTI, «The 'Jewish Nation' of Livorno: A Port Jewry on the Road to Emancipation» en Jews and Port Cities, 1590-1990: Commerce, Community and Cosmopolitanism, eds. D. Cesarani y G. Romain (London-Portland 2006) págs. 157-170. 
el ir muchos azotes, y continuando el ir llegó a saber y conocer las letras hebreas, que entonces sería de seis a siete años y las leía, e iba con los demás muchachos de la nación hebrea a la escuela ${ }^{48}$.

Una comparación entre este testimonio y aquel que se refiere a los marcos de educación primaria en Ferrara deja entrever por un lado ciertas similitudes y por el otro algunas diferencias fundamentales. En ambos casos existían marcos para la educación formal primaria, dirigidos a niños a partir de los 4-6 años y cuyo epicentro era la figura del maestro. Cabe señalar que cuando el texto, traducido del italiano, habla de escuela, en realidad se refiere a clase. En ambas ciudades existía más de una clase, a partir de lo cual podemos deducir, por un lado, que se trataban de marcos que podían aceptar números limitados de alumnos y, por el otro lado, que había suficientes niños que recibían educación formal lo cual se traducía en la necesidad de abrir varias clases. En el caso de Ferrara, sabemos que existían diferentes clases para niños de distintos grupos de edades. Respecto a este punto, el testimonio de Juan de León no ofrece suficiente información como para determinar si esta división también se encontraba en los marcos educativos en Liorna. En cuanto al sistema de estudio y los contenidos, en ambos casos el primer paso era la alfabetización en hebreo, inmediatamente seguido de la enseñanza de rezos. La principal diferencia a la que podemos apuntar tras la comparación de estos dos textos ${ }^{49}$, tiene que ver con la continuación de los estudios. Si bien ambos personajes se integraron al sistema de educación formal desde la más tierna edad, todo parece indicar que Díaz Nieto, educado en Ferrara, obtuvo una educación mucho más amplia y profunda, la cual se pone de manifiesto a través de sus los ricos conocimientos del idioma hebreo, los contenidos bíblicos y de la tradición rabínica, así como el hecho de haber estudiado directamente las fuentes talmúdicas -lo cual no pude decirse de la educación que recibió Juan de León en Liorna-.

Si el nivel de la educación formal primaria era en cierto modo un reflejo de la antigüedad y el grado de organización de la comunidad,

\footnotetext{
${ }^{48}$ Proceso contra Salomón Machorro (Juan de León), transcrito por B. LEwIN (Buenos Aires 1977) pág. 125.

${ }^{49}$ Cabe señalar que esta comparación, la cual toma en consideración sólo dos testimonios puntuales, es sólo un primer intento y no puede tomarse como prueba definitiva para llegar a conclusiones determinantes. Para ello habría que recurrir a documentos adicionales.
} 
los testimonios que nos llegan desde Francia corroboran esta teoría. De los documentos inquisitoriales que hemos podido rescatar y que hacen referencia a la educación primaria en territorio francés a lo largo del siglo XVII no hemos encontrado pruebas de que hayan existido escuelas judías en ésta época. Por el contrario, las declaraciones que poseemos describen un tipo de instrucción que tenía lugar principalmente en el ámbito familiar ${ }^{50}$. Así lo formula Duarte Gómez ante la Inquisición de Lima, quien vivió su infancia en Ruán a principios del siglo XVII:

Confesó que sus p[adr]es le havían enseñado la dicha ley de Moyses con oraciones y ayunos los quales havía hecho y guardado la dicha ley, llamando al Dios de Ysrrael con los dichos padres en sus ayunos oraciones y ceremonias en la ciudad de Ruan de Francia ${ }^{51}$.

Por un lado, el testimonio de Duarte Gómez se asemeja a tantos otros testimonios que se encuentran en los protocolos inquisitoriales, que describen el proceso de instrucción en el seno familiar en territorio español o portugués. Pero por el otro lado, este tipo de vivencia familiar era esencialmente distinto en Francia ${ }^{52}$, ya que dichas familias no vivían bajo el temor de la persecución inquisitorial.

Es importante aclarar que aunque en Francia aparentemente no había escuelas judías para niños durante el siglo XVII, esto no implica que la única fuente de formación haya sido el hogar. Por el contrario, y tal como veremos más adelante, en el caso francés, así como en el del resto de las comunidades de la diáspora sefardí, la sinagoga jugó un papel central y cumplía la función, no solamente de recinto de rezos y de lugar de reunión, sino que también se convirtió en el principal espacio donde los nuevos miembros, adultos incluidos, desarrollaban parte importante de su proceso de socialización y de aprendizaje. Aun así llama la atención

${ }^{50}$ Algunos de los testimonios tempranos sobre prácticas criptojudías en el sur de Francia en los años 30 del siglo XVII hacen referencia a tradiciones del šabat, Pésah, ayunos y kašrut (restricciones dietéticas) que se llevaban a cabo en la intimidad del hogar. Vid. ZiNK, «Être juif à Bayonne...», págs. 452-455.

${ }^{51}$ Proceso contra Graci Méndez de Dueñas, AHN-I, leg. 1648, exp. 16, fol. 8v.

${ }^{52}$ Otro ejemplo similar se encuentra en la declaración de Juan de Medina en la que describe sus años de infancia en Peyrehorade en Francia; vid. Proceso contra Fernando Medina, fol. 6r-v. 
que cuando en Bayona, por ejemplo, se contrató al doctor Ávila para que residiera en la ciudad y cumpliera varias funciones comunitarias, no se le solicitó servir como instructor de escuela ${ }^{53}$.

\section{LA SINAGOGA Y EL PROCESO DE SOCIALIZACIÓN}

Si en la mayoría de las comunidades judías normativas, el general del público había sido instruido desde la más temprana infancia en los conceptos, preceptos y rituales judíos, los individuos que pertenecían a estas comunidades de la diáspora sefardí en Europa occidental contaban con un bagaje de conocimientos muy diferente. Dada esta realidad, la sinagoga cumplía una función adicional: no solamente era el recinto de rezos, sino que se convirtió en el principal escenario para la educación judía adulta. Aunque a priori no se trataba de un marco educativo, de facto esta fue una de las principales funciones que cumplió en estas comunidades.

La sinagoga, como centro de la vida judía, era simultáneamente un medio y un fin: un medio, en cuanto a que era el espacio donde se facilitaba la reeducación judía de sus miembros; y un fin, al considerarse el lugar para la máxima expresión de la vida religiosa. Incluso la educación formal que recibían aquellos individuos que se adherían a la comunidad a tierna edad, se dedicaba en una primera etapa a capacitar al joven para su participación en los ritos sinagogales, tal como se puede apreciar en el testimonio de Araujo sobre el inicio de sus estudios en Venecia.

En la dicha escuela, en un libro de media quartilla en romançe, le enseñava el suso dicho [su maestro] a reçar, diciéndole hasta dónde avía

${ }^{53}$ Tal como señalamos arriba, según uno de los testimonios recibidos ante el tribunal de la Inquisición, las funciones oficiales de Ávila eran leer la Biblia, predicar judaísmo y realizar la circuncisión. Por su parte, NAHON («Terre D’Idolâtrie...», págs. 156-157) es de la opinión de que, de acuerdo con las cláusulas del contrato posterior de Ávila en Londres, otra de sus funciones en Bayona sería la de proporcionar instrucción religiosa a los niños y a las personas recién llegadas de las «tierras de idolatría». Sin embargo, en los documentos inquisitoriales analizados no hemos encontrado fuentes que corroboren esta opinión. 
de reçar de una vez y a dónde avía de parar, aguardando a los demás, para que fuesse a las sinagogas con los demás judíos ${ }^{54}$.

En el caso de las congregaciones criptojudías francesas del siglo XVII, la sinagoga ${ }^{55}$ ocupaba la función simultánea de centro ritual y lugar para la enseñanza, tanto para adultos como para niños en edad de escuela. Por ejemplo, Fernando Medina declara haber recibido una educación judía desde su infancia, pero sólo menciona la instrucción que recibió en el ámbito de la sinagoga:

Dijo que en el tiempo que estubo en su tierra, aunque de corta edad como tiene dicho, observó y guardó todo lo que observaban y guardaban los demás judaizantes, que por maior se acuerda, era ir a la sinagoga, y allí oir leer y explicar el libro de la ley, por uno como ministro de ello que se ponía en parte alta, como en forma de pulpito, en donde le leya y explicaba a los demás ${ }^{56}$.

En su experiencia en la sinagoga, los judíos nuevos se instruían en diversos aspectos del judaísmo. Ante todo, aprendían lo directamente relacionado a los rezos y los objetos rituales. En este contexto aprendían a reconocer y a utilizar el talit o manto ritual, los tefilín o filacterias, así como a familiarizarse con el sidur o libro de rezos ${ }^{57}$.

${ }^{54}$ Proceso contra Luis Franco, fol. 9v.

${ }^{55}$ Cabe señalar que en las diversas ciudades francesas de esta época, cuando se habla de sinagogas, no se trataba de edificios públicos consagrados exclusivamente a la vida comunitaria y ritual. Durante esta etapa se trataba de espacios limitados de reunión, generalmente en la casa de alguno de sus miembros o líderes; vid. G. NAHON y M. EscAmilla, «Matines juives à Bayonne au XVIIe siècle au filtre du Saint Office», en Non solo verso oriente - Studi sull'ebraismo in onore di Pier Cesare Yoly Zorattin, eds. M. D. B. Cotrozzi, R. di Segni y M. Massenzio (Florencia 2014) págs. 295-344: 314.

${ }^{56}$ Proceso contra Fernando Media, fol. 32r-v.

${ }^{57}$ Una interesante y completa descripción sobre los objetos rituales se encuentra en uno de los testimonios de Diego Díaz Nieto; vid. «Segundo proceso de Diego Díaz Nieto», en UCHMANy, La vida entre el judaísmo y el cristianismo, pág. 258. Véase también en Kaplan, «Cristóbal Méndez alias Abraham...», pág. 428. A Luis Méndez Chávez, habiendo salido de Ámsterdam, le fueron decomisados en Maracaibo, entre otros varios objetos, un manto ritual (descrito en el registro como «escapulario») y unas filacterias (descritas en el inventario como «correas de badona y taxas de palo»); vid. Proceso contra Luis Méndez Chávez, fol. 6r. Sobre el uso de objetos rituales en Bayona, vid. NAHON y Escamilla, «Matines juives à Bayonne...», pág. 335. 
De la declaración de Juan de León aprendemos también que la utilización de estos objetos rituales era una de las primeras costumbres que adoptaban los ex-conversos tras su llegada a las comunidades judías:

Como tiene confesado, lo llevaban a la dicha sinagoga y que solamente en ella se pusieron el tale, que es como una cobija o sábana, pero que él no rezaba los salmos ni oraciones de la dicha Ley porque no las sabía ni las aprendió ${ }^{58}$.

Según este testimonio, los nuevos judíos ya utilizaban el talit en las más tempranas fases de su proceso de socialización, incluso antes de dominar el general del ritual sinagogal y conocer las oraciones.

Los rezos en sí son uno de los temas descritos más frecuentemente y en mayor detalle en los testimonios ante la Inquisición, incluyendo sus tiempos, frecuencia, duración, contenidos, la interacción entre los diversos miembros y los idiomas y modos en que eran recitados.

Incluso en las congregaciones criptojudías de Francia que aún no eran oficiales ni del todo reconocidas, contamos con varios testimonios según los cuales desde épocas muy tempranas se llevaban a cabo rezos cotidianos. Así, por ejemplo, queda claro en la declaración de Rafael de Silva proveniente de Bayona en los años 40 del siglo XVII:

Por la mañana se levantaba y lavava y se ponía a rezar en un libro que tenía en la dicha casa, donde todos rezavan, y a la tarde bolvía a rezar otra vez con el dicho libro, y otras veces a la noche [...] y lo vio hacer las más de los días y en particular reparó que los sávados era la oras aun más largas ${ }^{59}$.

Otro testimonio dado en el proceso de Fernando Medina señala «que todos acudían a la sinagoga tres veces cada día a oír explicar la ley al ministro, por mañana, y a las tres de la tarde, y a la noche, en cada vez, por espacio de media hora poco más, $\mathrm{o}$, menos ${ }^{60}$.

A mediados del siglo XVII, en Bayona, y posiblemente en otras congregaciones criptojudías en Francia, se realizaban reuniones de rezo, fijas y cotidianas, todos los días de la semana, tres veces a día, tal como

\footnotetext{
${ }^{58}$ Proceso de Salomón Machorro (Juan de León), pág. 180.

${ }^{59}$ Proceso contra Diego Rodríguez Cardozo, fol. 17r-v.

${ }^{60}$ Proceso contra Fernando Medina, fol. 33r.
} 
lo manda el judaísmo normativo. Estos testimonios ante la Inquisición nos permiten comprender el grado de compromiso y el lugar central que dichas prácticas ocupaban en la vida de estos individuos. Por ejemplo, según los documento aquí citados, los miembros de estas congregaciones se reunían tres veces al día y dedicaban diariamente aproximadamente hora y media de su tiempo (y los sábados más) en rezos y pláticas de contenido religioso.

En cuando a los rezos, dos en particular son mencionados numerosamente en los archivos de la Inquisición, por su propio nombre, y en varias ocasiones también se recoge su contenido: el Šemá y la Amidá, siendo estos considerados también por el judaísmo clásico como las dos oraciones más importantes.

Algunos de los testimonios hacen referencia al modo como se recitaban. Un ejemplo de ello se encuentra en el testimonio de Baltasar Araujo, antes mencionado:

Aprendió de mem[ori]a las [oraciones] de la Shma y Amida que son las más forçossas, de que avía dicho de cada una un pedaço, y que no se acordava de las demás palabras porque con el mucho tiempo que avía que no las reçava [...] Para rezar la Amida se ponía derecho los pies juntos, inclinado el cuerpo, mirando hacia el dosel donde estavan los pergaminos de la ley y para rezar La Sema se sentava como los demás, cerrando los ojos al principio de la dicha oración ${ }^{61}$.

Este testimonio de Baltasar Araujo refleja su grado de socialización en la vida sinagogal. Araujo sabía con exactitud que estas dos eran las principales oraciones, así como también el modo como cada una de estas debía recitarse: la Amidá: de pie, con los pies juntos y en dirección al Arón Hacodeš -el arca sagrada-, donde se guardan los rollos de la Torá (en dirección a Jerusalén), y el Šemá, sentados y con los ojos cubiertos durante la primera parte de dicho rezo.

Testimonios de otros procesos incluyen transcripciones de estas oraciones, en boca de los procesados. Estos textos son un material muy valioso reflejo de las costumbres en las comunidades de la diáspora sefardí y a partir de las cuales podemos aprender varios aspectos sobre el proceso de socialización de los nuevos judíos en dichas congregaciones.

\footnotetext{
${ }^{61}$ Proceso contra Luis Franco, fols. 9v-10r.
} 
Uno de los hechos que llaman la atención sobre los registros de las oraciones en los protocolos inquisitoriales era el idioma en el que eran recitados. Tal como veremos en los ejemplos que traeremos a continuación, en algunos casos los reos recordaban los contenidos en su idioma original -hebreo-, y en su traducción al castellano, o sabían parte del rezo en hebreo y otra parte en español. En otros casos, los reos recitaban oraciones judías directamente en su traducción al castellano.

Diego Díaz Nieto recitó ante el Tribunal de la Inquisición el principio de la oración del Šemá, pronunciando primero el texto en hebreo, seguido de su traducción al español:

La oración de la Amidah que es compuesta de algunos psalmos y de profecías. Y que es tan larga que no se escribirá en un pliego de papel y que comienza: 'Adonay abre mis labios y mi boca pronunciará tus loores ${ }^{62}[\ldots$ ]$^{63} \mathrm{Y}$ antes de esta oración rezaban una oración que este sabe en la lengua hebrea en la cual está la Shema que dice: Shema Ysrael, Adonay Elohenu, Adonay Ehad, Barukh Shem Kvod Malkhuto LeOlam VaEd ${ }^{64}$. Quiere decir: 'Oye Israel, El Señor Adonay es Nuestro Dios, el Señor Adonay es Uno. Bendito sea el Nombre de su Glorioso Reino para siempre y siempre ${ }^{65}$.

${ }^{62}$ La versión que se encuentra en los libros de rezos traducidos al español de principios del siglo XVII es muy similar, si bien no idéntica. Este mismo versículo figura en una edición de Ámsterdam de 1662-1663 en los siguientes términos: «A. Mis labios abriras, y mi boca denunciará tu loor», véase Libro de Oraciones de mez y la orden de Hanukah, y Purim. Dispuesto con toda Curiozidad. Amsterdam. En Casa y a costa de David de Crasto (Castro?) Tartaz. Anno 5423 (1662-1663), fol. 91r. Esta formulación no fue modificada tampoco en las ediciones posteriores revisadas, hasta principios del siglo XVIII.

${ }^{63}$ Los tres puntos figuran en la citada trascripción de Uchmany; aparentemente, la fuente original incluye un fragmento adicional de la oración.

${ }^{64}$ La versión impresa de este proceso fue publicada con correcciones lingüísticas, también en castellano, según las normas ortográficas aceptadas en la actualidad. En general, en la gran mayoría de los casos en los que los documentos inquisitoriales incluyen palabras, frases o textos en hebreo, suelen presentar ciertas inexactitudes respecto al original en dicha lengua, tal como puede observarse en las citas a continuación. Esta oración fue transcrita por UCHMANY sin error alguno, tras haber aclarado en un pie de nota que «la oración hebrea se transcribió correctamente, ya que el escribano del Santo Oficio hizo en este caso muchos errores», véase allí, nota 39. En todo caso, a pesar de esto, no cabe duda que esta fuente demuestra que Diego Díaz conocía de memoria y a la perfección el rezo del Šemá en hebreo, su idioma original.

65 «Segundo proceso de Diego Díaz Nieto», en Uchmany, La vida entre el judaísmo y el cristianismo, pág. 257. 
Este texto llama la atención por su exactitud, pues aunque incluye sólo la primera parte de ambas oraciones, tanto el texto hebreo como el español son muy precisos. No olvidemos que el declarante, Diego Díaz Nieto, aunque provenía de una familia ex-conversa ibérica, nació en la ciudad de Ferrara y desde temprana edad recibió una educación formal judía. En este sentido no han de sorprendernos sus amplios conocimientos. Aunque el acusado no hace referencia al tipo de libro de oraciones que solía usar, podemos asumir que sabía utilizar el libro de rezos en hebreo -o al menos aquel que incluía tanto el texto en hebreo como la traducción al español-, ya que los libros de rezo de la época que sólo incluían la traducción al español, los cuales eran muy comunes en estas comunidades de la diáspora sefardí y fueron continuamente reeditados hasta el siglo XVIII, traen el primer versículo en fonética hebrea, sin traducción al español, y continuando posteriormente con la oración en español, como sigue: «Semah Israël .A. Elohenu .A. Ehad. Baruh Sem Kebod Malchutó Leholam Vahed. Y amaras à .A. tu Dio con todo tu coraçõ y con toda alma y con todo todo tu aver» ${ }^{66}$.

En su testimonio antes la Inquisición podemos ver que Díaz Nieto no solamente sabía recitar de memoria los rezos, sino que sabía traducir, al menos parte de ellas, del hebreo al español.

${ }^{66}$ Libro de Oraciones de mez, fols. 84v-85r; de este mismo modo figura también en ediciones posteriores: véase por ejemplo el Orden de las oraciones cotidianas. Por estilo seguido y corriente, con las de Hanucah, Purim, y Ayuno del Solo. Y las tres Pascuas, Pesah, Sebuoth, y Sucoth. A que se añaden las Parasioth, y Aphtaroth, que en todas estas Fiestas se leen. Nuevamente corregido y a su costa impresso por David Tartas, Amsterdam. Año 5452 (1691-1692) p. 49; Orden de las oraciones cotidianas. Por estilo seguido y corriente, Con las de Hanucah, Purim, y Ayuno del Solo. Como también las tres Pascuas de Pesah, Sebuoth, y Sucoth, y con las Parasioth, y Aftarot. Nuevamente corregido, por David de Elisa Pereyra. Amsterdam, Año 5493 (1713), pág. 48. Cabe señalar que todas estas son la misma traducción del libro de rezos al español, la cual fue revisada, corregida y republicada varias veces desde el siglo XVI hasta el XVIII. La traducción original fue realizada en Ferrara, Italia y publicada por primera vez en 1552. Sobre las ediciones y publicaciones de libros de rezos en la diáspora sefardí y en Ámsterdam en particular, vid. Y. H. YerushaLmi (ed. \& prol.), Meyer Kayserling Biblioteca Española-Portuguesa-Judaica and Other Studies in Ibero Jewish Bibliography by the Author, and by J.S. de Silva Rosa; with a Bibliography of Kayserling's Publications by M. Weisz (New York 1971); K. OfFENBERG, «Exame das tradições. Um estudo bibliográfico sobre as publicações dos primeiros sefardim nos Países Baixos stentrionais, especialente em Amesterdão», en Portugueses em Amesterdão 16001680, eds. R. Kistemaker y T. Levie (Amsterdam 1988) págs. 56-63; M. KayserLing, Biblioteca española-portugueza-judaica (Strasbourg 1890). 
Otros reos también declaran la utilización de ambos idiomas, hebreo y español, para recitar las oraciones. Veamos, por ejemplo, el testimonio de Juan de Medina:

Las principales [oraciones] que se acuerda hauer executado, y observado son una oración, que llaman el Zema, la qual es como sigue: Zema Israel, Adonai Eloeno, Adonai Ysad Barux, Zem que bot maljuto, leolam vaed, que en castellano quiere decir: oie Israel n[uest] ro Dios el señor dicho bendito su nombre su honra y su Reyno, para siempre y siempre. Y al t[iem]po de decirse esta oración, se ponía la mano derecha sobre la frente cerrados los ojos, y se iba deslizando la mano, asta pasar todo el rostro, y si tenía el libro de la reza en la mano con él, y si no sin él, y esta oración con otros psalmos de David, que estaban en los libros de las rezas, destinados para diferentes días, [...] se acuerda que rezaban también otra oración y esta la rezo muchas veces, la qual se decía: Lamida, y se rezaba en pie juntos los pies, y era muy larga. De ella no se acuerda, para poderla referir, solo que empezaba: Adonai mis lavios abriras, y mi voca pronincuara tu loor, o palabras semejantes a estas ${ }^{67}$.

Es altamente probable que lo que Juan de Medina sabía respecto a los rezos lo haya aprendido de un libro de oraciones en español. Si bien es cierto que menciona un versículo en hebreo, pero es justamente aquel que se incluía en fonética hebrea en dichos libros de oraciones en español ( $\sin$ ser traducido al español). Además, la traducción altamente imprecisa que ofrece de dicho versículo deja en entredicho que haya poseído conocimientos del idioma hebreo. Por el contrario, tenemos aquí el caso de una persona que conocía fragmentos de los rezos que recitaba del sidur en español, tanto el Šemá como la Amidá.

El hecho que los reos hayan mencionado parte de las oraciones en hebreo no implica que los susodichos hayan dominado dicho idioma. Por el contrario este uso lingüístico refleja el modo particular como se llevaban a cabo los rituales en el marco de estas comunidades de la diáspora sefardí.

En todo caso, entre el público que frecuentaba las sinagogas de las comunidades judías de la diáspora sefardí también había, naturalmente, personas que habían alcanzado distintos grados de conocimiento. Quienes ya vivían en la ciudad un tiempo considerable estaban mucho estaban más

\footnotetext{
${ }^{67}$ Proceso contra Fernando Medina, fol. $7 \mathrm{v}$.
} 
familiarizados tanto con los rezos y los servicios en la sinagoga, como con el resto de los preceptos y conceptos judíos. Los "nuevos", es decir, aquellos que se habían integrado a la comunidad recientemente, desconocían el servicio y su primer cometido consistía en aprender las bases de los rezos para poder participar en los rituales sinagogales. No olvidemos que muchos de estos conversos, aunque quizás hubiesen realizado grandes esfuerzos e incluso sacrificios para regresar al judaísmo, en realidad no poseían conocimientos firmes del judaísmo normativo. Como parte del intento de ayudar a los conversos en este complejo proceso de adaptación, dichas comunidades demostraron cierta flexibilidad en lo que respecta a la participación en los rituales en la sinagoga. Como la gran mayoría no sabía leer en hebreo fue común y aceptado el uso de libros de rezos en español, fenómeno que se refleja en las numerosas ediciones publicadas hasta el siglo XVIII. Los recién llegados eran acogidos de inmediato -en varios casos tras la circuncisión, como señalamos anteriormente- y se esperaba que participaran en la vida religiosa a pesar de las significativas brechas de conocimiento.

Si bien en las comunidades judías tradicionales existía la figura del hazán o cantor ritual encargado de dirigir los rezos, cabe señalar que en estas congregaciones, esta práctica constituía también uno de los medios para educar a los nuevos miembros, tal como señala en su declaración Méndez Chávez sobre la comunidad de Ámsterdam: «y uno de los judíos leía los psalmos que rezaban, por no alcanzar todos a leer o no saber» ${ }^{68}$. En algunas comunidades se puede reconocer un proceso gradual, tal como lo señala Araujo, quien en un primer momento recibió un libro de rezos en romance «y después que avía aprendido a reçar por el dicho libro le avían dado otro que tenía la una plana en castellano y la otra en hebreo» ${ }^{69}$. El testimonio de Cristóbal Méndez reitera ambas prácticas aquí mencionadas: la lectura en voz alta de los rezos, así como la oración individual en distintos idiomas ${ }^{70}$.

En el proceso contra Diego Rodríguez Cardoso (fols. 63v-64v) figura un testimonio muy detallado y extenso que incluye varios rezos en español. A continuación presentamos una comparación entre los textos de dichas oraciones según se encuentran, de una parte, en el proceso in-

\footnotetext{
${ }^{68}$ Proceso contra Luis Méndez Chávez, fol. 36r.

${ }^{69}$ Proceso contra Luis Franco, fol. 9v.

${ }^{70}$ Y. KAPLAN, «Cristóbal Méndez alias Abraham Franco de Silveyra...», pág. 425.
} 
quisitorial y, de otra, en uno de los libros de rezos en español impreso en Ámsterdam en los años 60 del siglo XVII ${ }^{71}$ :

\section{El rezo del Šemá}

\section{En el testimonio ante la Inquisición}

Sema Israel Adonai El loeno Adonai ea vane vara seuquebo malcuto leolan vahel. Y amarás Adonai tu Dio en su estar, en tu casa en la carrera en su echar, en tu levantar y ataras as por señal en tu mano y serán por tafali entre tus ojos y escribirlas as sobre unbrales en tu casa y en tus puertas y sera si hoyendo oyeredes mis encomendantes que yo os encomiendo a vos oy para amar a Adonai v[uest]ro Dio y para lo servir con todo vuestro corazon y con toda vuestra alma daré lluvia en vuestra tierra en su ora tenprana y tardia y cogeras tu civera tu mosto y tu aceite dare hierva en tu campo para tu quatropea y comeras y hartarte as y seales guardados a vos que no se sombaya vuestro corazón y vas a parte des cercades y vos umilledes a Dios y dixo Adonay a Moyses habla a los hijos de Israel y dirás a ellos digan ellos el seisi sobre alas de sus paños por sus generaciones ${ }^{72}$ verdad y cierta compuestas firme y derecha fiel amiga querida y codiciada.
En el libro de rezos (Ámsterdam, ca. 1660)

Semah Israël .A. Elohenu .A. Ehad. Baruh Sem Kebod Malchutó Leholam Vahed. Y amaras à .A. tu Dio con todo tu coraçõ y con toda alma y con todo todo tu aver. Y serán las palabras estas que yo te encomiendá oy sobre tu coraçon, y repetrilasás à tus hijos, y hablaras en ellas, en tu estar en tu casa $y$ en tu andar por la carrera y en tu echar y en tu levantar. Y atarlasás por señal sobre tu mano, y serán por Thephilin entre tus ojos. Y escrevirlasás sobre vmbrales de tu casa y en tus puertas. Y será si oyédo oyerdes à mis encomendáças que yo encomendan à vos oy para amar à .A. vuestro Dio y para lo servir, con todo vuestro coraçon y con toda vuestra alma: y daré lluvia de vuestra tierra en su hora temprana y tardia, y cogeras tu civera $\mathrm{y}$ tu mosto $\mathrm{y}$ tu alzeyte. $\mathrm{Y}$ darè yerva en tu campo para tu quatropea y comeras y hartarteás; Sed guardados à vos, que no se sombaya vuestro coraçon, y vos apartedes y sirvades à dioses atros: y vos humillades à ellos, $y$ erescerá furor de.A. en vos, y detendrá à los cielos, y no será lluvia, y la tierra no dara à su hermollo, y deperdervoshedes ayna de

${ }^{71}$ Téngase en cuenta que la versión del rezo ante la Inquisición fue recitada oralmente, mientras que la versión del libro de oraciones fue impresa, por lo que el recurso a acrónimos propio de los textos impresos no implica una diferencia entre versiones y, en lo tocante a la transcripción de voces hebreas, los posibles errores o inexactitudes bien podrían ser responsabilidad del secretario encargado de tomar nota del testimonio y no necesariamente achacables a la pronunciación del reo. Subrayamos las partes del rezo que fueron agregadas en la versión presentada ante la Inquisición y que no figuran en esta edición del libro de oraciones, y marcamos en cursiva las partes del rezo que fueron omitidas en la versión presentada ante la Inquisición; diferencias mínimas de formulación no se señalan.

${ }^{72}$ El versículo que aquí sigue ya no corresponde al rezo del Šemá sino a la plegaria que figura en los libros de rezos inmediatamente después. 
sobre la tierra la buena que.A. dan à vos. $Y$ pondredes à mis palabras estas sobre vuestro coraçon, y sobre vuestra alma, y atardes à ellas por señal sobre vuestra mano, y serán por Tephilin étre vuestros ojos, y abezaredes à ellas à vuestros hijos para hablar en ellas en tu estar en tu casa, y en tu andar por la carrera, y en tu echar, y en tu levantar. Y escrevirlas has sobre vumbrales de tu casa, $y$ en tus puertas: Por q' te muchiguen vuestros días y días de vuestros hijos sobre la tierra $q^{\prime}$ jurò .A. à vuestros padres para dar à ellos como días de los cielos sobre la tierra. Y Dixo .A. Moseh por dezir. habla à hijos de Israël y diras à ellos, y hagan à ellos Cicith sobre alas de sus paños por sus generancios: y den sobre el Cicith de la ala hilo cárdeno $Y$ será à vos por Cicith, y veredes à el, y membrarvoshedes de todas encomendanças de .A. y haredes à ellas, y no esculquedes empos vuestro coraçon y empos vuestros ojos, que vos errátes epos ellos. Por que vos membredes y hagades à todas mis encomendanças, y seades santos à vuestro D. Yo.A. vuestro Dio que saqué à vos de tierra de Egypto por ser à vos por Dio yo.A. vuestro Dio. Verdad y cierta, y compuesta, y firme y derecha, y fiel y amiga, y querida y cobeciada [...]

\section{El rezo de la Amidá}

\section{En el testimonio ante la Inquisición}

Adonai mis labios abrirás mi boca denunciaras en tu loor. Bendito tu Adonai nuestro Dio y Dio de nuestros padres Dios de Abraham Dios de Isaac Dios de Jacob el dio el grande el Barrangan el temerosso dio Alto galardona mercedes cría el todo miembro mercedes de padres traye Redimidor a hijos de tus hijos por su nombre con amor Rey ayudan y saluan Bendito tu Adonai anparo de Abrahan tu barragan para siempre adonai abre higrian muertos tu grande para
En el libro de rezos (Ámsterdam, ca. 1660)

A. Mis labios abriras, y mi boca denunciará tu loor. Bendito tu .A. N. D. y Dio de nuestros padres, D. de Abraham, Dio de Isahc Dio de Iahacób, el Dio el grãde, el barragã, y el temeroso. D. alto, gualardoná mercedes buenas criã el todo y membran mercedes de padres, y trayen redimidor à hijos de sus hijos por su nombre con amor: Rey ayudan y salvan y amparan. Bendito tu .A. amparo de Abraham. Tu barragan para siempre .A. abiviguã 
salvar hacen descender la lluvia gobiernan vidas abrigan muertos con piedad tu santo y tu nombre santto bendito tu Adonai el dio santo a lo qual desde dichas palabras tu santo se umillan y luego prosiguen bolbiendose a poner en pie $^{73}$ tu apiadas al hombre sabiduría a ver a al varon entendimiento bendito tu Adonay apiadan el saber hasnos tornar nuestro padre a tu ley y alleganos nuestro servicio melecinanos y seremos melecinados salvanos y seremos salvados bendito tu Adonai que melecinas enfermos de su pueblo Israel bendicenos nuestro Padre en toda obra de nuestra mano y bendice nuestro año con rocios de voluntad haznos tornar nuestros jueces como en principio $y$ alleganos nuestro servicio a los renegados no sea esperanza y a todos los herejes y a todos los malsines como punto serán de perdidos y todos nuestros enemigos oy van, serán atajados y prosiguen otras palabras de que no se acuerda y acaba assi:

Mi Dio guarda mi lengua de mal mis labios de hablar engaño mis maldientes mi alma calle como polvo en aval de sus consejos daría sus pensamientos sea por voluntad dichos de mi boca pensamientos de mi corazón delante ti Adonai mi dio mi remidor haz en paz en sus cielos el por sus piedades haga paz sobre nosotros y sobre todo Israel amen -y a el decir haz en paz se empiezan a partir del sitio de donde están y dan tres passos y $\underline{\text { se levantan en puntillas }}^{74}$. muertos tu, grande para salvar. En verano. Hazié decender el rocio. Goviernan bivos con merced abiviguan muertos con piedades $[\ldots]^{75}$ Tu santo, y tu nombre santo, $y$ sántos en todo dia te loaran. Bendito tu .A. el Dio el Sãto. En dia de Contricion (el Rey el santo). Tu apiadan al hombre sabiduria, y abezan à varon entendimiento, $\mathrm{y}$ apiadanos de contigo sabiduria, entendimiento, y entelecto. Bendito tu .A. apiadan el saber. Haz nos retornar nuestro padre à tu ley, y alleganos nuestro rey à tu servicio $[\ldots]^{76}$ Medezinanos .A. y seremos medezinados, salvanos, y seremos salvos $[\ldots]^{77}$ Bẽdito tu .A. medezinan enfermos de tu pueblo Israël. De pesah hasta 22 de Noviembre E.V. Bendizenos nuestro padre en toda obra de nuestra mano, y bẽdize nuestro año con rocio de voluntad $[\ldots]^{78}$ Haz tornar nuestros juezes como de primero y nuestros cósejeros como en principio, y aparta de nos ansia y suspiro, y reyna sobre nos ayna tu. A. à tus solas con piedades cõ justedad, y con juyzio. B.T. .A. aman justedad y juy-zio. (El Rey del Juyzio.) A los relegados no sea esperança a todos los herejes y todos los malsines como punto serán perdidos, y todos nuestros enemigos, $y$ todos nuestros aborresceintes ayna serán tajados $[\ldots]^{79}$

Mi Dio guarda mi lengua de mal, y mis labios de hablar engaño, y á mis maldicientes mi alma calle, y mi alma como polvo $a ̀$

${ }^{73}$ Este añadido corresponde a una explicación que el reo incluye.

${ }^{74}$ Este añadido corresponde a una explicación que el reo incluye.

${ }^{75}$ La siguiente parte del rezo fue omitida en la oración recitada ante la Inquisición. En el sidur este es el texto que continúa: «caydos, y medezinan enfermos [...] Kedusah [...]».

${ }^{76}$ En el sidur continúa: «y haz nos tornar [...]».

${ }^{77}$ En el sidur continúa: «q nuestro loor tu. Y haz subir medezina $[\ldots] »$.

${ }^{78}$ En el sidur continúa: «bendicion y grado: [...]».

${ }^{79}$ El texto que sigue en el sidur, el cual el reo mismo sabía que seguía pero había declarado haberlo olvidado, comienza: «y reyno de la sobervia ayna arrancaras [...]». 
todo sea, Abra mi coraçon en tu ley, y empos tus encomendanças siga mi alma, y todos los levantãtes sobre mi para mal ayna balda su consejo, y daña sus pensamientos. Sean por voluntad dichos de mi boca, y pensamientos de mi coraçon delante de ti .A. mi fuerte $y$ mi redemidor. Hazien paz en tus cielos por sus piadades haga paz sobre nos y sobre todo Israël Amen.

La gran similitud de estos dos textos, provenientes de fuentes tan distintas, es impactante y mucho se puede aprender de ello. Entre los muros del tribunal inquisitorial de Toledo, en medio de una España que prohibía rotundamente la presencia judía, como también cualquier libro judío, este reo recordaba de memoria largas partes de las principales oraciones judías. Si bien había olvidado algunos fragmentos, lo que se acordaba, que era la mayoría, era recitado, palabra a palabra, con las mismas formulaciones, tal como figuraba en los libros de oraciones en traducción al español que se encontraban en las sinagogas de la diáspora sefardí. No cabe la menor duda que este reo había utilizado asiduamente alguna de las ediciones del libro de rezos en español que fueron revisadas y reimpresas a partir de su primera edición publicada en Ferrara en 1552. Salvo casos muy extraños, en España y Portugal no se contaba con libros de oraciones. Sabían recitar de memoria lo que habían aprendido durante su estancia en comunidades judías y llama la atención la gran exactitud de los contenidos. Este hecho evidentemente refleja un proceso de socialización profundo y un grado de conocimiento que confirman que su contacto con el judaísmo no fue una cuestión esporádica.

Aparentemente los rezos públicos en muchas de estas comunidades eran conducidos en hebreo y las traducciones al español eran para el uso personal de aquellos miembros que no tenían capacidad para leer hebreo. No obstante, también aquí el caso francés pasa por un proceso interesante y peculiar. Desde los años cuarenta del siglo XVII los conversos en Francia ya contaban con libros de rezos, aparentemente en cantidad suficiente para cada uno de los individuos que participaban en las reuniones, incluidos los que estaban de paso. Sin embargo, en una primera etapa los 
rezos comunitarios no se conducían en hebreo ${ }^{80}$ y la lectura en voz alta de las oraciones se hacía directamente en español ${ }^{81}$, ya que en esta época, en Francia no tenían dominio del hebreo:

Tomó cada uno un libro de la reza que llevaba de su casa, menos los que no savían leher, que esos no hacían más que atender ${ }^{82}$ Y el mismo Diego Rodríguez Cardosso como dueño de la casa ${ }^{83}$ enpezó la reza de la mañana, que son diferentes psalmos de David en Romance con este principio: me dio el alma que diré en mi limpia, ella tú la criaste y tú la formaste e la soplaste entre mí y tu aparejado para tornarla a ti ${ }^{84}$. Y prosigue con otras palabras de que ahora no se acuerda, y haviendo empezado el dicho Diego Rodríguez Cardosso empezaron también a referir y rezar lo mismo todos los demás en tono vajo. Y haviendo acabado dicho Rodríguez Cardosso, aguardó a que acabasen los demás lo qual y todos avían rezado que heran los dichos psal$\operatorname{mos}[\ldots]^{85}$.

Las comunidades de la diáspora sefardí, si bien fueron fundadas por cristianos nuevos que retornaron al judaísmo, tenían rabinos que contaban con un rico bagaje de conocimientos sobre el judaísmo normativo. Eventualmente también las comunidades de Francia contaron con guías

${ }^{80}$ Existe un testimonio que indica que antes de la llegada de Ávila a Bayona había un hombre llamado Joseph Enríquez que leía en hebreo. Sin embargo, aparentemente hasta la llegada de Ávila, la lectura pública de las oraciones se realizaba generalmente en español; vid. Proceso contra Diego Rodríguez Cardozo, fols. 206v-207r.

${ }^{81}$ Véase un ejemplo adicional en el Proceso contra Graci Méndez de Dueñas, fol. 55r-v.

${ }^{82}$ Llama la atención este comentario, tomando en consideración que un porcentaje muy alto de los cristianos nuevos sabían leer y escribir.

${ }^{83}$ NAHON y EsCAmilla («Matines juives à Bayonne...», pág. 314) señalan que los rezos se llevaban a cabo la casa de Isaac Israel de Ávila, hasta su partida a Londres en 1674, tras lo cual los rezos fueron trasladados simultáneamente a las casa de Albaro Luis, Jacob Gómez y Diego Rodríguez Cardoso. El presente testimonio fue presentado en los años sesenta sobre una visita a realizada a Francia en 1646, con lo cual queda establecido que la casa de Rodríguez Cardoso funcionó como centro ritual en época anterior y posterior a los años de servicio de Ávila en la ciudad.

${ }^{84}$ Con este versículo comienza la oración matutina de Šajarit. En el libro de rezos impreso en Ámsterdam en los años treinta figura la misma traducción, con algunas leves diferencias: «Mi Dio el alma que diste en mi limpia tú la criaste, tú la formaste, tú la asoplaste en mi, y tu la guardas entre mi, y tu aparejado para tomarla de mí, y para hazerla tornar en mi al aparejado para venir» (Libro de Oraciones de mez, fols. 4v-5r).

${ }^{85}$ Proceso contra Diego Rodríguez Cardozo, fol. 63r. 
de este tipo. Sin embargo, en esta fuente vemos reflejada una realidad en la cual, en una primera etapa, a falta de otra autoridad religiosa en territorio francés, eran los propios miembros criptojudíos quienes se encargaban de liderar la vida religiosa. Diego Rodríguez Cardoso fue sin lugar a dudas una prominente figura en la congregación de Bayona en la primera mitad del siglo XVII. Era un hombre muy pudiente y cabecilla de una amplia red comercial entre España y Francia. Sin embargo, no solamente que no contaba con capacitación rabínica ni estudios judaicos formales, sino que además, hasta donde tenemos noticias, nunca residió en el seno de ninguna comunidad judía fuera de Francia. Aun así, aquí vemos que era común que soliera dirigir los rezos públicos en español, porque seguramente el hebreo no era un idioma que dominara o pudiera leer.

Esta fuente también llama la atención porque demuestra que incluso en las congregaciones embrionarias ${ }^{86}$, los rituales no se limitaban únicamente a las oraciones principales de la Amidá y el Šemá, sino que incluían las plegarias completas, según figuran en los libros de rezo. Además, el hecho que el reo que testificaba ante el tribunal de la Inquisición haya recordado de memoria también estos versículos, nos enseña que eran recitadas comúnmente en los ritos que llevaban a cabo públicamente. En este sentido cabe considerar la existencia y difusión de los libros de rezos traducidos al español como un factor determinante en el proceso de instrucción a la litúrgica judía.

Tras la llegada a Francia de líderes religiosos provenientes de otras comunidades como Ámsterdam a partir de mediados del siglo XVII, se adoptó de modo general el uso del hebreo en la lectura oficial de los rezos. A partir de esta etapa, la práctica se asemejaba a la de las otras comunidades de la diáspora sefardí. Es decir, que se leía en voz alta en hebreo y cada cual realizaba su oración personal en el idioma que sabía leer ${ }^{87}$, que en la mayoría de los casos era el español:

[...] cada uno tenía su libro en la mano, y leía lo que el ministro explicaba, el qual lo leya y explicaba, en lengua hebrea, aunque los demás

${ }^{86}$ Para otros testimonios sobre los rezos públicos en Saint Espirit, vid. NAHON y EsCAMILLA, «Matines juives à Bayonne...», págs. 323-325.

${ }^{87}$ Véase otro ejemplo, en el Proceso contra Diego Rodríguez Cardozo, fol. $205 \mathrm{v}$. 
tenían libros cada uno en la lengua que entendía ${ }^{88}$, y que asistía este como los demás a dichas juntas, y por no sauer la lengua hebrea, tenía el libro en romance, en lengua castellana, que por hauer en aquella villa mucha concurrencia de castellanos, se aprende y habla con facilidad ${ }^{89}$.

De hecho, los cambios que tuvieron lugar en las congregaciones francesas a consecuencia de la llegada de líderes religiosos fueron más allá de la inclusión del idioma hebreo en la práctica ritual. Por ejemplo, poco tiempo después de la llegada del doctor Ávila a Bayona ${ }^{90}$, lo que antes eran reuniones de rezos reducidas en casas de particulares, se transformó en un rezo principal en la casa del susodicho, quien «tomó una casa donde tiene una mui buena sala concurrían en ella los mas de los observantes de dicha ley a rezar» ${ }^{91}$. Además, sabemos que el doctor Ávila instruyó a los miembros de la congregación en varios otros aspectos del judaísmo normativo $^{92}$ y toda esta instrucción, según parece, tuvo lugar en el contexto de la actividad sinagogal. Este ejemplo constituye una prueba más de la función central que jugó la sinagoga no solamente como lugar de reunión y oración, sino también como el espacio principal donde tenía lugar el proceso de reeducación básica al judaísmo normativo.

Otro de los principales canales de educación que tenían lugar en estas sinagogas eran las explicaciones y los sermones que en ellas ofrecían los rabinos, tal como vemos en el testimonio de Méndez Chávez:

Y de allí adelante le llebaban a la sinagoga, adonde abía puesto un pulpito grande en medio deella y allí se subía el rabi y descogía un pergamino en que estava escripta la ley de Moisés y llamaban a ocho o nueve ${ }^{93}$ que

${ }^{88}$ Cabe señalar que cuando aquí se afirma que se rezaba individualmente «cada uno en la lengua que entendía» no se refería a que haya habido traducciones de los rezos a diversos idiomas, sino que cada uno rezaba en hebreo o en la traducción que existía, que era al español.

${ }^{89}$ Proceso de Fernando Medina, fol. 33r.

${ }^{90}$ Según NAHON («Terre D’Idolâtrie...», pág. 154), Ávila ya se encontraba en Bayona desde los años cincuenta del siglo XVII.

${ }^{91}$ Proceso contra Diego Rodríguez Cardozo, fol. 225r-v.

${ }^{92}$ Proceso contra Diego Rodríguez Cardozo, fols. 205v y 224r.

${ }^{93}$ En general, el número de personas que son llamadas a la Torá varía entre tres, los lunes y los jueves, y siete, los sábados. Este procedimiento era seguido también en la sinagoga de Ámsterdam. Cuando Méndez Chávez habla de ocho o nueve personas, 
avían de ser descendientes de los sacerdotes de las tribus ${ }^{94}$ y leían dicha ley y luego el dicho rabino predicaba esplicándola y apoyando que aquella era la ley buena en que se podían salvar y no las demás ${ }^{95}$.

Méndez Chávez señala que los sermones eran parte integral y central en el rito sinagogal. Del mismo modo como la práctica ritual se llevaba a cabo de forma que los nuevos integrantes pudieran por un lado participar desde el primer momento y por el otro lado, no se sintieran avergonzados por su ignorancia mientras aprendían gradualmente lo referente a los servicios en la sinagoga, en este contexto también los sermones cumplían una función educativa de primera importancia. Tal como Saperstein señala ${ }^{96}$, la comunidad de Ámsterdam (y en cierta medida puede aplicarse a otras comunidades de esta diáspora) estaba compuesta, entre otros, por individuos sofisticados; muchos de ellos llegaban a Ámsterdam después de haber sido educados en universidades portuguesas o españolas, mientras que otros eran exitosos mercaderes internacionales. Sabían que querían ser judíos, pero llegaban no solamente con una gran brecha de conocimientos, sino también con las limitaciones lingüísticas que no les permitían leer los textos originales en hebreo. Los sermones que se ofrecían en la sinagoga debían presentar la esencia de la tradición judía de forma tal que fuera adecuada a su nivel intelectual y relevante a su mentalidad cultural. Estas prédicas constituían un constante programa para la educación adulta de los nuevos judíos. La principal característica de estos sermones fue que debían ser, por un lado, de un nivel intelectual lo suficientemente alto para interesar al público educado pero, por otro lado, también debían ser accesibles e ilustrativos para los menos intelectuales y debía tomar en cuenta sus limitados conocimientos sobre la cultura rabínica.

posiblemente esté incluyendo a quienes eran llamados para cargar el rollo de la Tora (el magvia) y a quien lo enrrollaba (el golel).

${ }^{94}$ En la lectura tradicional de los rollos de la Torá en la sinagoga, es costumbre rendir honor y dar prioridad en el orden de la lectura a los descendientes de los cohanim (sacerdotes) y los leviim, en recuerdo a la función que los susodichos cumplían en los servicios en el Templo de Jerusalén, o tal vez en ocasión de fiestas familiares cuando se permitían más aliot.

${ }^{95}$ Descripción de la comunidad de Ámsterdam en el Proceso contra Luis Méndez Chávez, AHN-I, leg. 1620, exp. 09, fols. 35v-36r.

${ }^{96}$ M. SAPERSteIn, Exile in Ámsterdam - Saul Levi Morteira's Sermons to a Congregation of "New Jews" (Cincinnati 2005) págs. XVI-XVII. 
El surgimiento y auge de las comunidades judías de la diáspora sefardí en Europa occidental es un interesante y peculiar fenómeno en los anales de la historia judía de la temprana Edad Moderna, considerada por algunos investigadores como pieza fundamental y necesaria para la comprensión del proceso de modernización de la sociedad judía en general. Dadas las circunstancias particulares, tanto sociales y religiosas como económicas, estas comunidades presentan características que las diferencian del resto de las congregaciones judías de su época. No son muchos los casos en los que fuentes documentales claramente extrañas, lejanas, ajenas e incluso hostiles pueden servir de fuente fidedigna y confiable para la reconstrucción de procesos que involucran la dinámica interna de comunidades judías. Sin embargo, y tal como hemos intentado demostrar en el presente artículo, los documentos celosamente recopilados y conservados por la Inquisición española contienen importantes testimonios que nos ayudan a comprender varios aspectos del proceso de socialización de los exiliados ibéricos tras su llegada a estas comunidades judías en Europa occidental.

Recibido: 11/01/2016

Aceptado: 13/04/2016 